\section{Hair analysis for screening horses for exposure to dietary toxic residues}

\author{
Mark Dunnett \\ Bury St. Edmunds, Suffolk, UK
}

\section{Introduction}

Hair analysis is a diagnostic technique utilised in humans and animals that can identify and assess past exposure of individuals, groups and populations to various harmful/toxic substances in the environment. Hair is a living tissue comprising the follicle and the hair shaft. Three hair types occur in equine skin; the temporary coat hair, the permanent mane and tail hair, and the tactile hairs around the muzzle and eyes. Hair is predominantly protein, but contains many other components including water, lipids, melanins and minerals. Equine hair has a cyclical growth pattern, beginning with an extended period of growth (anagen) during which the follicle actively forms the hair shaft. After a non-growing phase (telogen), shedding of the hair shaft is effected by the underlying formation of a new hair shaft. Equine mane and tail grows at a rate of $18-25 \mathrm{~mm} / \mathrm{month}$ and varies with breed and anatomical location, but is not affected by change in season (Dunnett and Lees 2003). Residues of numerous harmful xenobiotics can be deposited in hair during the lifetime of the hair shaft including prohibited substances (drugs), pesticides, mycotoxins, heavy metals and other toxic elements, and plant toxins. A single hair shaft sample, unlike a one-off blood or urine sample, can discriminate between a single acute toxin challenge, repeated dosing or chronic exposure. In contrast, hair root analysis can identify recent acute exposure.

\section{Prohibited substances}

Various substances regarded as prohibited substances (drugs) under equine competition rules can be present in equine feedstuffs and supplements. They occur as natural constituents, or feed crop or manufacturing contaminants. Salicylates and dimethylsulphoxide (DMSO), both anti-inflammatories, are present in many equine feedstuffs and pasture species. Salicylate is readily detected in hair, especially in horses fed comparatively high alfalfa diets. Hair analysis can discriminate between horses on high and low salicylate-containing diets. Morphine and codeine from Papaverum spp and atropine and hyoscine Datura spp can contaminate feed crops and grazing, and have been detected in post-race urine samples. Morphine has been detected in mane hair of horses after up to 3 months after experimental administration at doses of 0.1 and $0.7 \mathrm{mg} / \mathrm{kg}$ body weight, and morphine contents in hair were correlated to dose (Beresford et al. 1998). Codeine deposition has not been studied in equine hair, however it has been detected in human and rat hair either experimentally or in drug abusers (Charles et al. 2005, Scheidweiler et al. 2005). Neither atropine nor hyoscine appears to have been detected in hair from any species. Caffeine and theobromine are equine feed contaminants and have been detected in tail hair $(<0.1 \mathrm{ng} / \mathrm{mg}$ ) 13 months after oral caffeine administration (Dunnett et al. 2002). Dietary supplements can be contaminated with anabolic steroids, steroid hormone precursors and stimulants. Hair analysis has been used to detect steroid administration in horses. Both boldenone and stanozolol residues have been identified in mane and tail hair up to 12 months after a one-off administration (Popot et al. 2002). Testosterone has also been detected in equine hair after a single intra-muscular injection (Popot et al. 2004). Although not sought in equine hair, stimulants such as ephedrine have been found in hair of bodybuilders (Dumestre-Toulet et al. 2002).

\section{Pesticides}

Pesticide deposition in hair has been studied in humans and animals. (Dauberschmidt and Wennig 1998) identified residues of DDE and other polychlorinated biphenyls (PCBs) in human hair, and lindane and DDT residues were detected in hair from children (Neuber et al. 1999) and dogs (Liu and Pleil 2002). Covaci et al. (2002) observed greater residues of PCBs, $\mathrm{HCH}$ and DDT in hair from occupationally exposed subjects compared with non-exposed controls. Dioxin residues have also been identified in human hair, with residue levels 2.5 times greater in occupationally exposed workers than in the general population (Nakao et al. 2005). As yet, few data exist to link hair pesticide residues to dietary exposure. Despite the potential of hair analysis to identify pesticide exposure there are no reported studies of this in horses.

\section{Heavy metals and other toxic elements}

Hair analysis can evaluate human exposure to heavy metals, including cadmium $(\mathrm{Cd})$, lead $(\mathrm{Pb})$, mercury $(\mathrm{Hg})$, molybdenum (Mo) and nickel ( $\mathrm{Ni}$ ) including relationships between body burden, dosage, and toxicity, and residue levels in hair (Shamberger 2002). Ward and Savage (1994) studied Pb, $\mathrm{Cd}$ and $\mathrm{Ni}$ exposure in horses by hair analysis. $\mathrm{Pb}$ and $\mathrm{Cd}$ levels in hair and blood arising from traffic pollution were elevated and significantly correlated $(r=+0.69)$. Anke et al. (1989) observed increased $(p<0.01$ ) hair $\mathrm{Cd}$ residues in horses grazing near metal smelters compared with those on unpolluted grazing. Hair Mo concentrations in horses were strongly correlated with dietary Mo intake $(p<0.02)$ (Cape and Hintz 1982). Wells et al. (1987) reported that hair $\mathrm{Ni}$ contents were indicative of dietary $\mathrm{Ni}$ intake and that a direct correlation existed between hair $\mathrm{Ni}$ contents in mares and their foals on the day of foaling $(p<0.02)$. Human hair analysis is a good indicator of dietary $\mathrm{Hg}$ exposure and is the method of choice to identify exposure to methylmercury (Wilhelm and Idel 1996), but there is no equivalent evidence in horses. Selenium $(\mathrm{Se})$ is readily detected in equine hair and variation in concentration reflects differences in chronic exposure to Se containing forage. Potentially toxic levels of $\mathrm{Se}$ in blood have been correlated $(r=0.76-0.96)$ with hair concentrations (Dewes and Lowe 1987, Witte et al. 1993). Hair analysis for arsenic (As) has not been reported in horses, but it has been used in the examination of As toxicosis in cattle. Riviere et al. (1981) reported hair As levels of 0.80-3.40 $\mathrm{ng} / \mathrm{mg}$ in affected cattle, in contrast to values of $0.09-0.10$ $\mathrm{ng} / \mathrm{mg}$ in randomly selected controls. In humans, As residues 
can be detected up to 30 days after they become undetectable in other tissues (Lin et al. 2004).

\section{Mycotoxins}

Hair analysis to detect mycotoxin exposure in horses has not been reported, however two studies describe the detection of fumonisins in human hair. Sewram et al. (2001) detected residues of fumonisins B1 and B2 (FB1 and FB2) in hair samples from subjects in following chronic exposure to fumonisin contaminated maize. Acute exposure was also identifiable by hair analysis, in rats, four weeks after administration of FB1 at doses of 1 and $10 \mathrm{mg} / \mathrm{kg}$ body weight (Sewram et al. 2003).

\section{Plant toxins}

Plant toxicoses can arise from ingestion of poisonous plants during grazing when normal pasture is starved or in preserved forage. Common ragwort (Senecio jacobaea) poses the most serious threat as this injurious weed is widespread and contains hepatotoxic and carcinogenic pyrrolizidine alkaloids (PA). As the greatest health risk from PA arises from chronic ingestion, a retrospective test, such as hair analysis, would be appropriate to monitor exposure. In a recent study, PA residues were absent in hair from horses with no known exposure and from most with suspected exposure, however PA residues were tentatively identified, at concentrations up to 250 $\mathrm{pg} / \mathrm{mg}$, in sequential hair sections from one horse. Data suggested of ragwort ingestion 20 months prior to hair sampling.

\section{Discussion and conclusions}

Hair is a unique biological matrix for the retrospective determination of exposure to a range of ingested toxins. Continuous growth of mane and tail hair produces a permanent longterm historical record of exposure which can be studied in further detail if sectional analysis of the hair shaft is performed. However, several tissue specific factors may need to be considered when interpreting hair analysis data. Hair colour greatly effects drug residue levels measured in equine hair. Black hair can contain concentrations up to forty-fold greater than white hair (Dunnett et al. 2004). However, hair colour can have both positive and negative effects on residue levels of some toxic elements (Asano et al. 2005). Given the nature of the hair growth cycle, telogen hair is considerably older than anagen hair and lacks a vascular supply. Excess numbers of telogen hairs in samples can distort residue distribution profiles and artifactually reduce measured values. Unlike urine, which mainly contains drug metabolites, parent drugs are predominantly detected in hair. In conclusion, hair analysis in horses has the potential to be an effective means of identifying past exposure to a range of dietary toxins.

\section{References}

Anke M., Kosla T. and Groppel B. (1989): The cadmium status of horses from central Europe depending on breed, sex, age and living area. Arch Tierernahr 39, 657-683

Asano K., Suzuki K., Chiba M., Sera K., Matsumoto T., Asano R. and Sakai T. (2005): Influence of coat colour on the trace elemental status measured by particle-induced X-ray emission in horse hair. Biol Trace Elem Res 103, 169-176
Beresford G. D., Gourdie T. A. and Whittem E. (1998): Analysis of morphine in equine hair samples by GC/MS. Proceedings of the 12th International Conference of Racing Analysts and Veterinarians., Vancouver, BC, Canada, R \& W Publications, Newmarket, UK.

Cape L. and Hintz H. F. (1982): Influence of month, colour, age, corticosteroids and dietary molybdenum on mineral concentration of equine hair. Am J Vet Res 43, $1132-1136$

Charles B. K., Day J. E., Rollins D. E., Andrenyak D., Ling W. and Wilkins D. G. (2005): Opiate recidivism in a drug treatment program: comparison of hair and urine data. J Anal Toxicol 29, 76-77

Covaci A., Tududaki M., Tsatsakis A. M. and Schepens P. (2002): Hair analysis: another approach for the assesment of human exposure to selected persistent organochlorine pollutants. Chemosphere 46, 413-418

Dauberschmidt C. and Wennig R. (1998): Organochlorine pollutants in human hair. Letter. J Anal Toxicol 22, 610-611

Dewes H. F. and Lowe M. D. (1987) Suspected selenium poisoning in a horse. NZ vet J 35, 53-54

Dumestre-Toulet V., Cirimele V., Ludes B., Gromb S. and Kintz P. (2002): Hair analysis of seven bodybuilders for anabolic steroids, ephedrine, and clenbuterol. J Forensic Sci 47, 211 -214

Dunnett M., Houghton E. and Lees P. (2002): Deposition of etamiphylline and other methylxanthines in equine mane hair following oral administration. Proceedings of the 14th International Conference of Racing Analysts and Veterinarians, Orlando, USA, R \& W Publications, Newmarket, UK

Dunnett M. and Lees P. (2003): Trace element, toxin and drug elimination in hair with particular reference to the horse. Res Vet Sci 75, 89-101

Dunnett M., Richardson D. W. and Lees P. (2004): Detection of enrofloxacin and its metabolite ciprofloxacin in equine hair. Res vet Sci 77, 143-151

Lin C. J., Wu M. H., Hsueh Y. M., Sun S. S. and Cheung A. L. (2004): Tissue distribution of arsenic species in rabbits after single and multiple parenteral administration of arsenic trioxide: tissue accumulation and the reversibility after washout are tissue-specific. Cancer Chemother Pharmacol 55, 170-178

Liu S. and Pleil J. D. (2002): Human blood and environmental media screening method for pesticides and polychlorinated biphenyl compounds using liquid extraction and gas chromatography-mass spectrometry analysis. J Chromatogr B 769, 155-167

Nakao T., Aozasa O., Ohta S. and Miyata H. (2005): Survey of human exposure to PCDDs, PCDFs, and coplanar PCBs using hair as an indicator. Arch Environ Contam Toxicol 49, 124-130

Neuber K., Merkel G. and Randow F. F. E. (1999): Indoor air pollution by lindane and DDT indicated by head hair samples of children. Toxicol Lett 107, 189-192

Popot M. A., Stoilijkovic N., Garcia P., Richard C. A., Bonnaire Y. and Tabet J. C. (2002): Additional studies on the detection of drugs in horse hair samples. 14th International Conference of Racing Analysts and Veterinarians, Orlando, USA, R \& W Publications, Newmarket, UK

Popot M. A., Stojilikovic N., Budillon A., Garcia P., Bonnaire Y. and Tabet J.-C. (2004): GC/EI-MS-MS method development for the detection of anabolic drugs in horse hair samples. Proceedings of the 15th International Conference of Racing Analysts and Veterinarians, Dubai, UAE, R \& W Publications Ltd., Newmarket, UK

Riviere J. E., Boosinger T. R. and Everson R. J. (1981): Inorganic arsenic toxicosis in cattle. Mod Vet Pract 62, 209-21 1

Scheidweiler K. B., Cone E. J., Moolchan E. T. and Huestis M. A. (2005): Dose-related distribution of codeine, cocaine and metabolites into human hair following controlled oral codeine and subcutaneous cocaine administration. J Pharmacol Exp Ther 313, 909-915

Sewram V., Mshicileli N., Shephard G. S. and Marasas W. F. (2003): Fumonisin mycotoxins in human hair. Biomarkers 8, 110-118

Sewram V., Nair J. J., Nieuwoudt T. W., Gelderblom W. C., Marasas W. F. and Shephard G. S. (2001): Assesing chronic exposure to fumonisin mycotoxins: the use of hair as a suitable non-invasive matrix. J Anal Toxicol 25, 450-455

Shamberger R. J. (2002): Validity of hair mineral testing. Biol Trace Elem Res 87, 1-28 
Ward N. I. and Savage J. M. (1994): Elemental status of grazing animals located adjacent to the London Orbital (M25) motorway. Sci Total Environ 146, 185-189

Wells L., Ralston S. L., LeRoy R. and Eck P. (1987) Factors influencing mineral content of horse hair. Proc Equine Nutr Physiol Soc Symp, Equine Nutrition \& Physiology Society

Wilhelm M. and Idel H. (1996) Hair analysis in environmental medicine. Zentralbl Hyg Umweltmed 198, 485-501
Witte S. T., Will L. A., Olsen C. R., Kinker J. A. and Miller-Graber P. (1993): Chronic selenosis in horses fed locally produced alfalfa hay. J Am Vet Med Assoc 202, 406-409

\section{Dunnett}

Equine Reserach and Diagnostics

PO Box 319, Bury St. Edmunds, Suffolk, IP28 6SY UK

info@erd.uk.com

\section{Fat adaptation affects insulin sensitivity and elimination of horses during an $80 \mathrm{~km}$ endurance ride}

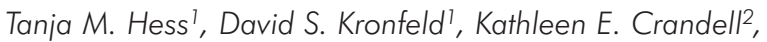
Jeannie N. Waldron ${ }^{3}$, Kimberley H. Treiber' ${ }^{l}$ W. Burton Staniar?', Marco A. Lopes ${ }^{4}$ and Patricia A. Harris ${ }^{5}$

Department of Animal and Poultry Sciences, Virginia Polytechnic Institute and State University, College of Agiculture and Life Sciences, Blacksburg, VA', KC Equine Consulting, The Plains, VA ${ }^{2}$. Rectortown Equine Clinic, Rectortown, VA ${ }^{3}$, Universidade Federal de Viçosa, BR $^{4}$ and WALTHAM Centre for Pet Nutrition, Melton Mowbray, UK

\section{Introduction}

Feeding feeds rich in fat and fiber (FF) may avoid the adverse effects on insulin sensitivity and insulin signaling associated with chronic adaptation to meals of grain and molasses (starch and sugar, SS) (Hoffman et al. 2003; Treiber et al. 2005a). This adverse effect of SS has been observed in resting horses but not when they are physically conditioned (Treiber et al. 2005b). It was revealed, however, when the fit horses were subjected to endurance exercise on a treadmillinsulin sensitivity and related variables were lower in horses adapted to SS compared to FF (Treiber et al. 2005b). The present study tested the hypothesis that insulin sensitivity would be lower in horses adapted to SS than those adapted to FF during an endurance race.

\section{Material and Methods}

The effects of feeds rich in starch and fat on insulin sensitivity were compared in 40 endurance horses during an $80 \mathrm{~km}$ race in 3 dietary groups: one experimental feed (SS) was rich in starch (33\%), low in fat (8\%); another (FF) was low in starch $(6 \%)$ and rich in fat (15\%); and commercial concentrates (CC) were intermediate in starch (16\%) and fat (11\%). Feeds were isoenergetic ( $23.3 \mathrm{Mcal} / \mathrm{kg} \mathrm{DM})$ and isonitrogenous $(\sim 12 \% \mathrm{CP})$. Horses were fed 1.7 to $5.1 \mathrm{~kg} / \mathrm{d}$ with hay ad libi- tum for 3 mo prior to the race. Blood samples were taken the day before the race (PRE), within 3 minutes of arrival at each vet check (after 27,48,80km), and three hours post completion or elimination. Plasma samples were analyzed for glucose, insulin, cortisol, CK and AST. A proxy for insulin sensitivity as measured by the minimal model was calculated: RISQI $=(1 /$ sqrt [insulin]) (Treiber et al. 2005c). Also, a proxy for pancreatic $\beta$-cell response to plasma glucose was calculated: MIRG $\left.=[\text { 800-0.30([insulin] }-50)^{2}\right] /$ [glucose - 30] (Treiber et al. 2005c). Effects of sampling time, completion of the ride, treatments and interactions were evaluated by ANOVA in a mixed model with repeated measures; non-parametric ANOVA compared finishers and eliminated horses for glucose, insulin, RISQI and MIRG.

\section{Results}

Reasons for elimination of 15 of the 40 horses (37.5\%) were lameness (3: 1FF, $2 \mathrm{CC}$ ), exertional rhabdomyolysis (2: $1 \mathrm{CC}, 1$ SS), failure to recover heart rate in $30 \mathrm{~min}$ (3: 2 SS, $1 \mathrm{CC}$ ), labile heart rate (2: $1 \mathrm{FF}, 1 \mathrm{SS})$, arrhythmias (2: $1 \mathrm{FF}, 1 \mathrm{CC})$, slow gut sounds (1 CC), sore back (1 FF), and rider option (1 CC).

Eliminated horses had overall lower $(P=0.037)$ RISQI $(0.26 \pm 0.01 \mathrm{mU} / \mathrm{L}-0.5)$ than finishing horses $(0.29 \pm 0.01$ $\mathrm{mU} / \mathrm{L}-0.5)$. Eliminated horses had overall higher $(P=0.015)$ insulin $(21.14 \pm 1.7 \mathrm{mU} / \mathrm{L})$ than finishing horses $(15.19 \pm 1.0$ $\mathrm{mU} / \mathrm{L})$. Eliminated horses had higher insulin specifically at 48 $\mathrm{km}(P=0.012)$ and at REC $(P=0.002)$ compared to finishing horses. Eliminated horses (analyzed without the rhabdomyolysis cases) had higher $C K$ at $48(P<0.001)$, and recovery $(P$ $<0.001$ ) than finishing horses. Eliminated horses (analyzed without the rhabdomyolysis cases) had higher AST at $48 \mathrm{~km}$ $(P=0.005)$, and recovery $(P<0.001)$ than finishing horses. Eliminated horses had overall higher cortisol (131.1 \pm 10.2 $\mathrm{ng} / \mathrm{dl}$ ) than finishing horses (1 19.9 $\pm 4.7 \mathrm{ng} / \mathrm{dl})$. Specifically at recovery cortisol was lower $(P=0.005)$ in finishers than eliminated horses.

Increases were found in plasma CK, AST, cortisol, and RISQI, and decreases in insulin and MIRG with sampling time $(P<0.005)$. Horses fed SS and CC had overall lower $(P=0.019)$ RISQI than FF fed horses. MIRG, however just had a trend to be lower $(P=0.088)$ in FF fed horses compared to SS and CC fed horses. Horses fed SS (17.7 $1.6 \mathrm{mU} / \mathrm{L}$ ) and CC $(18.6 \pm 1.8 \mathrm{mU} / \mathrm{L})$ feeds had overall higher insulin than FF $(13.6 \pm 0.9 \mathrm{mU} / \mathrm{L})$ fed horses. 
Horses on SS diets had higher plasma CK (11516 \pm 5116 $\mathrm{IU} / \mathrm{L})$ than FF $(514 \pm 34 \mathrm{IU} / \mathrm{L})$ or CC $(461 \pm 40 \mathrm{IU} / \mathrm{L})$ diets (P $<0.001)$. Eliminated horses on SS diet had the highest CK values compared to all other horses $(\mathrm{P}<0.001)$. Horses on SS diets had higher plasma AST $(669 \pm 163 \mathrm{IU} / \mathrm{L})$ than FF $(273 \pm 7 \mathrm{IU} / \mathrm{L})$ or $\mathrm{CC}(280 \pm 7 \mathrm{IU} / \mathrm{L})$ diets $(\mathrm{P}<0.001)$.

\section{Discussion}

The results of this study suggest that insulin resistance can be a determining factor in the elimination of horses during endurance races. Furthermore, supplementation with feeds high in fat and fiber can attenuate insulin resistance as shown by a higher RISQI in FF fed horses.

Two horses were eliminated with signs of rhabdomyolysis and eliminated horses had higher muscle enzymes at 27, $48 \mathrm{~km}$ and at recovery. Higher enzymes were also found in SS fed horses. High fat/ low carbohydrate diets have been shown to lead to lower muscle enzymes after exercise in severely affected horses with recurrent rhabdomyolysis cases (McKenzie et al. 2003). Such diets have been recommended to reduce rapid glycogen synthesis in horses with polysaccharide storage myopathy (Annandale et al. 2004). Excitable horses are also more prone to rhabdomyolysis, and they may become calmer when fat adapted (Holland et al. 1996).

Higher plasma cortisol levels in eliminated horses indicate that eliminated horses were more stressed than finishers. Also diets rich in starch have been shown to increase cortisol during exercise, due to increased excitement (Slade et al. 1975, Crandell et al. 1999). Cortisol increases insulin resistance (Guyton and Hall 2001), which is could be compensated for with increased insulin secretion as observed in this study.

Exercise usually enhances insulin sensitivity (Brun et al. 1995; Powell et al. 2002). During exercise, glucose transport is driven by the $\mathrm{Ca}^{++}$mediated GLUT-4 transport in addition to the insulin mediated GLUT-4 transport (Richter et al. 2004) leading to increases in insulin sensitivity. In all horses proxies indicated that insulin sensitivity increased with exercise throughout the race. In eliminated horses however, insulin sensitivity was overall lower. No differences in plasma glucose were found despite differences in insulin sensitivity, a result of compensation by an increased insulin response (MIRG).

Higher insulin could lead to decreased lipolysis (Saltiel and Kahn 2001) decreasing fatty acid oxidation during exercise, and contributing to decreased performance and elimination as observed in this study.

Lower insulin sensitivity (RISQI) in SS and CC horses, and in eliminated horses indicated that insulin resistance (low RISQI) was attenuated by fat and fiber feeding and also decreased the likelihood of elimination. Higher insulin sensitivity in finishers and fat and fiber fed horses may have allowed a more efficient glucose uptake by muscles, allowing energy to be obtained through fatty acid oxidation.

\section{Conclusion}

Fat and fiber feeding could avoid insulin resistance, improving the efficiency of energy utilization and performance of horses during endurance races. FF feeds could also reduce excitement and avoid increases in muscle enzymes. This study presents the first results to show a potential link between insulin resistance as a cause or effect of elimination during an endurance race.

\section{References}

Annandale E. J., Valberg S. J., Mickelson J. R. and Seaquist E. R. (2004): Insulin sensitivity and skeletal muscle glucose transport in horses with equine polysaccharide storage myopathy. Neuromuscular Disorders 666-674

Brun J. F., Guintrand-Hugret C., Boegner C., Bouix O. and Orsetti A. (1995): Influence of short term submaximal exercise on parameters of glucose assimilation analyzed with the minimal model. Metabolism 44, 833-840

Crandell K. G., Pagan J. D., Harris P. A. and Duren S. E. (1999): A comparison of grain, oil and beet pulp as energy sources for the exercised horse. Equine Vet J 30, 485-489

Guyton and Hall (2001): Textbook of medical physiology. Philadelphia, PA: W.B. Saunders Company, 875

Hoffman R. M., Boston R. C., Stefanovsky D., Kronfeld D. S. and Harris P. A. (2003): Obesity and diet affect glucose dynamics and insulin sensitivity in Thoroughbred geldings. Journal of Animal Science 81, 2333-2342

Holland J. L., Kronfeld D. S. and Meachem T. N. (1996): Behavior of horses is affected by soy lecithin and corn oil in the diet. Journal of Animal Science 74, 1252-1255

McKenzie E. C., Valberg S. J., Godden S. M., Pagan J. D., MacLeay J. M., Geor R. J. and Carlson G. P. (2003): Effect of dietary starch, fat, and bicarbonate content on exercise reponses and serum creatin kinase activity in equine recurrent rhabdomyolysis. J Vet Intern Med 17, 693-701

Powell D. M. and Reedy S. E, (2002): Session DR, Fitzgerald BP. Effect of short term exercise training on insulin sensitivity in obese and lean mares. Equine Vet J 34, 81-84

Richter E. A., Nielsen J. A., Jorgensen S. B., Frosig C., Birk J. B. and Wojtaszewski F. P. (2004): Exercise signslling to glucose transport in skeletal muscle. Proc Nutr Soc 63, 211-216

Saltiel A. R. and Kahn C. R. (2001): Insulin signaling and the regulation of glucose and lipid metabolism. Nature 414, 799-806

Slade L. M., Lewis L. D. and Quinn C. R. (1975): Nutritional adaptations of horses for endurance type performance. Proceedings of the 4th Equine Nutr Physiol Symp 4, 114-128

Treiber K. H., Boston R. C., Kronfeld D. S., Staniar W. B. and Harris P. A. (2005a): Insulin sensitivity and the somatotropic axis in growing Thoroghbred horses are affected by diet. J Anim Sci, in press.

Treiber K. H., Hess T. M., Kronfeld D. S., Boston R. C., Geor R. J., Freire M. S., Silva A. M. G. B. and Harris P. A. (2005b): Dietary energy sources affect insulin sensitivity and -cell responsiveness of trained Arabian geldings during endurance exercise. Proc American Academy of Veterinary Nutrition Symposium, June 1 st 2005b, 9, J Anim Nutr Physiol., in press

Treiber K. H., Kronfeld D. S., Hess T. M., Boston R. C. and Harris P. A. (2005c): Insulin sensitivity and pancreatic _-cell response in the horse: screening proxies and reference quintiles assessed by the minimal model. Am J Vet Res, in press

T. M. Hess

Department of Animal and Poultry Sciences irginia Polytechnic Institute and State University College of Agiculture and Life Sciences

Blacksburg, VA

thess@vt.edu 